\title{
Inversion Study on Initial Field of PM2.5 Transport Model with the Adjoint Method
}

\author{
Youli Shen ${ }^{1}$, Shaofeng Zhang ${ }^{1}$, Ning $\mathrm{Li}^{2}$ and Chunhua Zhang ${ }^{1, *}$ \\ ${ }^{1}$ Beihai Marine Environmental Monitoring Center, SOA, Beihai 536000, China \\ ${ }^{2}$ School of science, Dalian jiaotong University, Dalian 116028, China \\ ${ }^{*}$ Corresponding author
}

\begin{abstract}
According to the transport characteristics of PM2.5 and adjoint assimilation scheme, a PM2.5 adjoint assimilation model was constructed. Two ideal distributions of PM2.5 initial field were prescribed by the pollution condition of Chinese mainland. Experiment results indicated that mean absolute errors (MAEs) of observations and inverted results, and MAEs of inversion results and prescribed distribution decreased greatly after assimilation. The inversion results were also nearly equal to the prescribed distributions, indicating that this model could efficiently invert the PM2.5 initial field. Besides, the inversion efficiency could be raised if ratio of effective observations was increased.
\end{abstract}

Keywords-adjoint assimilation; initial field; effective observation

\section{INTRODUCTION}

Numerical model is one of the most effective ways to investigate PM2.5 [1-3]. The initial filed is the most important factors in PM2.5 simulation, which is often obtained from interpolation or other techniques. The 4-dimensional variational (4D-Var) data assimilation technique involved the adjoint method, which is one of the most effective and powerful approaches, was used by several researchers to estimate the initial conditions. In Elbern et al. [4] 4D-Var was applied to assimilate chemistry observations into a comprehensive tropospheric gas phase mode to find the correct initial values for a subsequent atmospheric model. Zhao et al. [5] applied the adjoint method to invert the model parameters and optimize the initial COD concentrations. Wang et al. [6] applied the adjoint model to estimate the initial total nitrogen distribution in the Bohai Sea. In our study, the adjoint method is applied to the PM 2.5 transport model, and the PM 2.5 initial filed is estimated.

\section{MODEL}

Based on the wind background field, an advection-diffusion equation of PM2.5 involved in this study can be of the form:

$$
\frac{\partial C}{\partial t}+u \frac{\partial C}{\partial x}+v \frac{\partial C}{\partial y}=\frac{\partial}{\partial x}\left(A_{H} \frac{\partial C}{\partial x}\right)+\frac{\partial}{\partial y}\left(A_{H} \frac{\partial C}{\partial y}\right)+\theta
$$

Where $C$ represents the PM2.5 concentration, $u$ and $v$ are the horizontal wind velocity in $x$-coordinate and $y$-coordinate, respectively, $A_{H}$ is the horizontal diffusivity coefficient, and $\theta$ is the source term.
According to the typical theory of Lagrangian multiplier method, the adjoint equation can be developed, which is in the following form

$$
-\frac{\partial C^{*}}{\partial t}=\frac{\partial\left(u C^{*}\right)}{\partial x}+\frac{\partial\left(v C^{*}\right)}{\partial y}+\frac{\partial}{\partial x}\left(A_{H} \frac{\partial C^{*}}{\partial x}\right)+\frac{\partial}{\partial y}\left(A_{H} \frac{\partial C^{*}}{\partial y}\right)-K_{C}(C-\bar{C})(2)
$$

Where $C^{*}$ is the adjoint variable of $C$, and $K_{c}$ is the weight coefficient of observations. The cost function $\mathrm{J}$ with respect to the initial PM2.5 value $C^{1}$ is calculated as

$$
\frac{\partial J}{\partial C^{1}}=\left(\frac{\partial C^{*}}{\partial t}\right)^{1}+\left(\nabla \cdot \vec{V} C^{*}\right)^{1}+\nabla \cdot\left(A_{H} \nabla C^{*}\right)^{1}
$$

The computing area and the distribution of routine monitoring stations are depicted in Fig. 1. The domain is encompassed over China $\left(70^{\circ} \mathrm{E} \sim 140^{\circ} \mathrm{E}, 20^{\circ} \mathrm{N} \sim 55^{\circ} \mathrm{N}\right)$. The horizontal resolution for the model is $0.5^{\circ} \times 0.5^{\circ}$. The integral time step is 600 s and the assimilation window is 5 days. The background wind filed data are derived from the National Centers for Environmental Prediction (NCEP) winds daily averaged for each $2.5^{\circ}$ latitude by $2.5^{\circ}$ longitude regions.

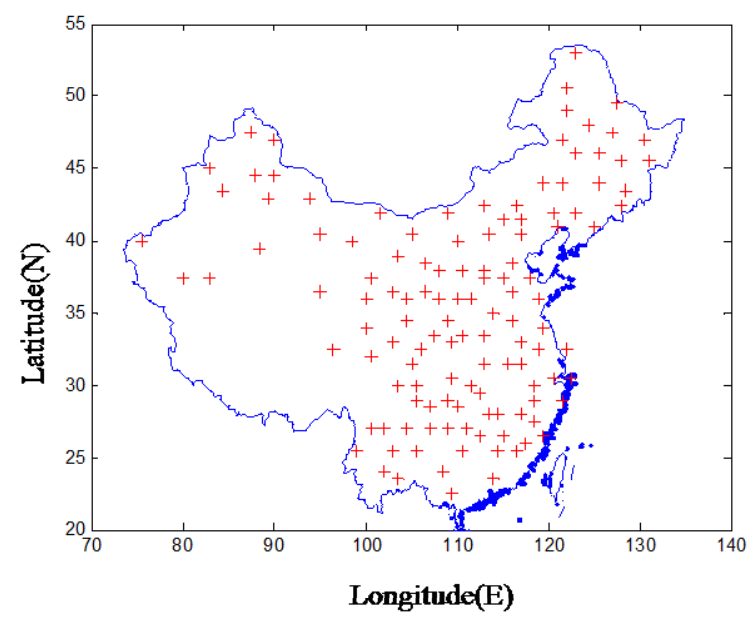

FIGURE I. THE COMPUTING AREA AND LOCATIONS OF THE OBSERVATIONS.

\section{EXPERIMENTS AND RESULTS}

Two types of ideal initial PM2.5 distributions are 
prescribed by the real PM2.5 condition in China, which is shown in Figure 2, in which (a) and (b) will be marked as PD1-PD2, respectively. The initial guess value of PD1 and $\mathrm{PD} 2$ are prescribed as $35 \mu \mathrm{g} / \mathrm{m}^{3}$ 和 $80 \mu \mathrm{g} / \mathrm{m}^{3}$. The iteration steps are set as 300. Experiments of PD1 and PD2 inversion are marked as Ex1 and Ex2.

The inversion results can be evaluated by the difference between 'observations' and simulated values, and the mean absolute error (MAE) between the prescribed and the inverted distribution. Differences between inverted results and observations and MAEs between inverted results and prescribed distributions are depicted in Table 1 , and the inversion results are shown in Figure 3. MAEs of observations and inverted results decrease by at least $84.8 \%$, and MAEs of distributions decrease by at least $48.8 \%$. The inversion results are also relatively similar to the prescribed distributions. We can deduce that the adjoint method has a strong ability of inverting the prescribed PM2.5 initial distributions.

TABLE I. MAES OF SIMULATED RESULTS AND OBSERVATIONS AND MAES OF INVERTED AND PRESCRIBED DISTRIBUTIONS.

\begin{tabular}{ccccc}
\hline \multirow{2}{*}{ Experiment } & \multicolumn{2}{c}{$\begin{array}{c}\text { MAE of observations } \\
\left(\boldsymbol{\mu g} / \mathbf{m}^{\mathbf{3}}\right)\end{array}$} & \multicolumn{2}{c}{$\begin{array}{c}\text { MAE of distributions } \\
\left(\boldsymbol{\mu g} / \mathbf{m}^{\mathbf{3}}\right)\end{array}$} \\
\cline { 2 - 5 } & $\begin{array}{c}\text { Before } \\
\text { assimilation }\end{array}$ & $\begin{array}{c}\text { After } \\
\text { assimilation }\end{array}$ & $\begin{array}{c}\text { Before } \\
\text { assimilation }\end{array}$ & $\begin{array}{c}\text { After } \\
\text { assimilation }\end{array}$ \\
\hline Ex1 & 17.86 & 0.31 & 5.66 & 0.93 \\
Ex2 & 1.78 & 0.27 & 1.27 & 0.65 \\
\hline
\end{tabular}
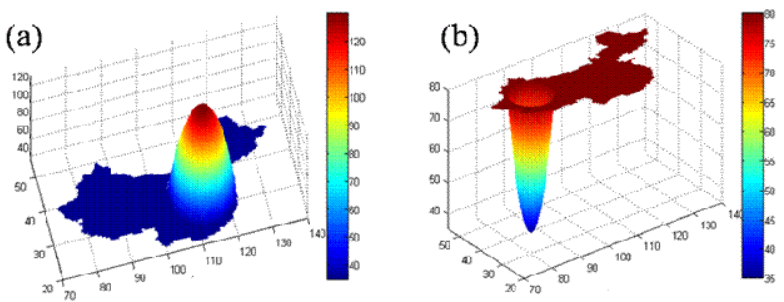

FIGURE II. TWO TYPES OF PRESCRIBED IDEAL INITIAL PM2.5 DISTRIBUTIONS (a)

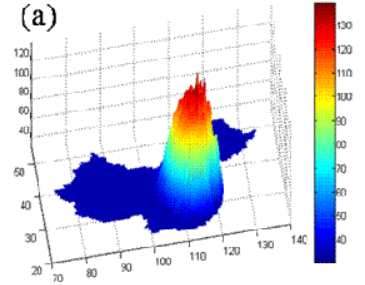

(b)

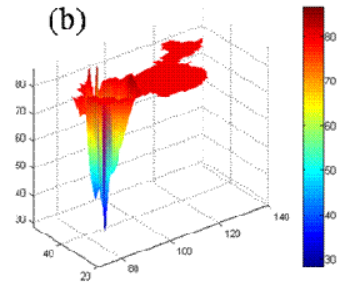

FIGURE III. THE INVERSION RESULTS AFTER ASSIMILATION

The initial guess values are selected as those distributed in most regions of the prescribed distributions. Observations are actually not implemented in regions where initial guess values are equal to prescribed distributions; in other regions they play decisive roles. Observation points where initial guess values are unequal to prescribed distributions are marked as 'effective observation points (EOPs)'. The number of EOP is 60 for PD1, while 6 for PD2 which might be not enough for inversion. PD2 are not commendable inverted compared to PD1. We guess that lack of EOPs in Ex2 is the main reason. In order to verify our guess, observations on the east of $113^{\circ} \mathrm{E}$ are deleted, and in the west China observation points are increased 54 (Figure 4(a)). Red, blue and white plus signs are represented as the deleted, preserved, and increased observations, respectively.

Inversion results are depicted in Figure 4(b). We can find that the inversion result is significantly improved by increasing EOPs. The MAE of observations is decreased from $1.27 \mu \mathrm{g} / \mathrm{m}^{3}$ to $0.33 \mu \mathrm{g} / \mathrm{m}^{3}$, decreasing by $74.0 \%$ which is obviously greater than that of Ex2. MAE of inversion result and prescribed distribution is decreased by $98.6 \%$. The number of EOP takes a significant effect on the inversion result, and inversion result will be largely improved by increasing the number of EOP.
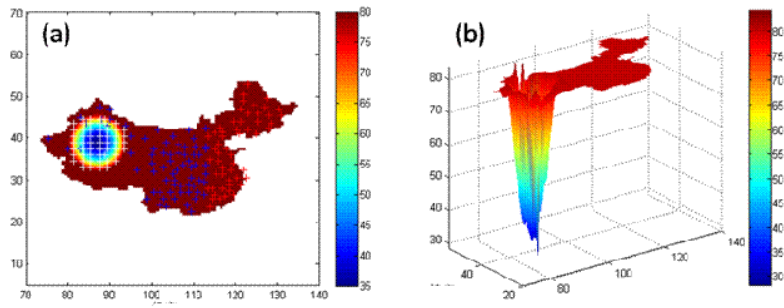

FIGURE IV. SET UP OF OBSERVATIONS (A) AND INVERSION RESULT AFTER ASSIMILATION (B)

\section{CONCLUSIONS}

The initial filed is often obtained from interpolation or other techniques, which inevitably causes large simulation errors. In this study, a PM2.5 adjoint assimilation model was constructed to invert the PM2.5 initial concentration. Two distributions were prescribed by the pollution condition of Chinese mainland. This model was applied to inverting the forementioned two distributions. Experiment results indicated that MAEs of observations and inverted results, and MAEs of inversion results and prescribed distribution decrease greatly after assimilation. The inversion results were also nearly equal to the prescribed distributions, indicating that PM2.5 initial field could be efficiently inverted by this model. Besides, the inversion efficiency could be raised if EOPs was increased.

\section{ACKNOWLEDGMENT}

Partial support for this research was provided by the director Fund of Marine Science and Technology, South China Sea Branch, State Oceanic Administration People's Republic of China (SOA) (1648) and the Public science and technology research funds projects of ocean (201305023-5).

\section{REFERENCES}

[1] Xue W., Fu F., Wang J., et al. Numerical study on the characteristics of regional transport of PM2.5 in China [J]. China Environmental Science (In Chinsese with English Abstract), 2014, 34(6): 1361-1368.

[2] Wang Q., Wu J., Lin Y. Implementation of a dynamic linear regression method on the CMAQ forecast of PM2.5 in Shanghai [J]. Acta Scientiae Circumstantiae (In Chinese with English Abstract), 2015, 35(6): 1651-1656.

[3] Mao L., Qiu Y., Kusano C., et al. Predicting regional space-time variation of PM2.5 with land-use regression model and MODIS data. [J]. Environmental Science \& Pollution Research, 2012, 19(1): 128-38.

[4] Elbern H., Schmidt H., Ebel A. Variational data assimilation for 
tropospheric chemistry modeling [J]. Journal of Geophysical Research, 1997, 102(1021): 15967-15986

[5] Wang C. H., Li X. Y., Lv. X. Q. Numerical Study on Initial Field of Pollution in the Bohai Sea with an Adjoint Method [J]. Mathematical Problems in Engineering, 2013, 2013(4): 389-405.

[6] Zhao Q., Hu X. M., Lv X. Q., et al. Study on the Transport of COD in the Sea Area Around Maidao off Qingdao Coast Using Data Assimilation [J]. Journal of Ocean University of China, 2007, 6(4): 339-344. 